\title{
O EDUCADOR DE JOVENS E ADULTOS E SUA FORMAC̣̃̃O
}

Leôncio Soares*

RESUMO: Este artigo versa sobre a formação inicial do Educador de Jovens e Adultos a partir dos resultados de estudo realizado no curso de Pedagogia de uma Universidade Federal. Desde a criação da habilitação (1986), a pesquisa analisa a pertinência da profissionalização desse educador, o significado da formação inicial em EJA para professores e egressos da habilitação e a inserção desse educador no campo de trabalho. Revelou-se o quanto é fértil analisar os processos de formação e atuação desses profissionais, por meio da reconstrução de suas trajetórias, e conclui-se que, mesmo com a crescente visibilidade que tem tido a EJA, tanto na instância das práticas quanto na dos estudos e pesquisas, ainda não existe efetiva demanda para uma formação específica. A formação do educador da EJA pode contribuir para o fortalecimento e a (re)configuração desse campo e, conseqüentemente, para o melhor atendimento a parcelas significativas da população que foram precocemente excluídas das ações de escolarização.

Palavras-chave: Educação de Jovens e Adultos; Formação Inicial; Profissionalização do Educador

\section{EDUCATORS OF YOUNGSTERS AND ADULTS AND THEIR EDUCATION}

ABSTRACT: This article discusses pre-service teacher education based on the results of a study done in the Pedagogy course in a federal university. Since the establishment of the program in 1986, the research has analyzed the aptness in the professional education of the educators, the meaning of having specific teacher pre-service training and continued education, and finally, the placement of the alumni in the work market. This study reveals how fertile it is to analyze the process of education and the performance of these professionals by reconstructing their trajectories. It concludes that despite the increased practice and research of adult education in Brazil, there is not an effective demand for this specific pre-service education program yet. The professional development of educators of youngsters and adults can contribute to the (re)configuration of the work field, and consequently, to providing better service to a significant portion of a public excluded from schooling.

Keywords: Adult and Youngster Education; Initial Training; Educator Professional education

\footnotetext{
* Professor do curso de Pedagogia e do Programa de Pós-Graduação em Educação da Faculdade de Educação da Universidade Federal de Minas Gerais, membro do Núcleo de Educação de Jovens e Adultos dessa faculdade e do Fórum Mineiro de EJA. E-mail: formacaoeja@yahoo.com.br
} 


\section{INTRODUÇÃO}

Este trabalho apresenta reflexões sobre a formação inicial do educador de jovens e adultos a partir dos resultados de uma pesquisa desenvolvida no período de 2003 a 2005 que visou compreender a atuação desse educador, egresso do curso de Pedagogia de uma Universidade Federal. Buscou-se analisar a trajetória profissional desses sujeitos, os locais de trabalho e seus olhares sobre o período em que cursaram a habilitação.

De acordo com André e Romanowski (1999), Haddad (2000), Machado (2000), Fonseca e Pereira (2000), Kleiman (2000), Ribeiro (1999), Vóvio e Biccas (2001), é ainda pequeno, apesar de crescente, o número de pesquisas específicas sobre a formação inicial dos docentes para a educação de jovens e adultos. Sobre os egressos da habilitação de EJA dos cursos de Pedagogia, em especial, são ainda mais raros os estudos.

Para esta pesquisa, realizamos um levantamento do universo dos egressos do curso, desde a sua criação, em 1986, até 2002, e enviamos um questionário com questões sobre o sujeito, sua formação na universidade e sua inserção no campo de trabalho. Foram entrevistados os egressos selecionados entre aqueles que responderam ao questionário e professores que atuaram e, em alguns casos, ainda atuam, no curso. Além disso, a pesquisa promoveu seminários para a discussão das condições de formação e atuação dos educadores de EJA, com a participação dos sujeitos da pesquisa.

\section{OS EDUCADORES EM FORMAĈ̣̃O}

A profissionalização do educador de EJA tem se tornado cada vez mais nuclear, tanto nas práticas educativas quanto nos fóruns de debate. Com base na ação do voluntariado, a primeira Campanha Nacional de Educação de Adultos no Brasil, lançada em 1947, passou a ser sistematicamente criticada por não preparar adequadamente professores para trabalhar com essa população. No I Congresso Nacional de Educação de Adultos, realizado no Rio de Janeiro, ainda em 1947, já eram ressaltadas as especificidades das ações educativas em diferentes níveis e se recomendava uma preparação adequada para se trabalhar com adultos. Passados mais de dez anos, no II Congresso Nacional de Educação de Adultos, realizado em 19581, as críticas à ausência de formação específica para o professorado, assim como à falta de métodos e conteúdos pensados particularmente para a educação de adultos, tornaram-se ainda mais agudas, explícitas e generalizadas. 
Ainda que não seja uma questão propriamente nova, somente nas últimas décadas o problema da formação de educadores para a EJA ganhou dimensão mais ampla. Esse novo patamar em que a discussão se coloca relaciona-se à própria configuração do campo da Educação de Jovens e Adultos. Nesse sentido, a formação dos educadores tem se inserido na problemática mais ampla da instituição da EJA como um campo pedagógico específico que, desse modo, requer a profissionalização de seus agentes.

Como consta da V CONFINTEA:

A educação de adultos engloba todo o processo de aprendizagem, formal ou informal, onde pessoas consideradas "adultas" pela sociedade desenvolvem suas habilidades, enriquecem seu conhecimento e aperfeiçoam suas qualificações técnicas e profissionais, direcionando-as para a satisfação de suas necessidades e as de sua sociedade. A educação de adultos inclui a educação formal, a educação não-formal e o espectro da aprendizagem informal e incidental disponível numa sociedade multicultural, onde os estudos baseados na teoria e na prática devem ser reconhecidos. (Declaração de Hamburgo sobre Educação de Adultos, V CONFINTEA, UNESCO, 1997 , p. 42)

O inciso VII do art. $4^{\circ}$ da LDB 9394/96 estabelece a necessidade de atenção às características específicas dos trabalhadores matriculados nos cursos noturnos. Vê-se, assim, a exigência de formação específica para atuar na EJA, explicitada pelo Parecer CEB/CNE 11/2000: "Trata-se de uma formação em vista de uma relação pedagógica com sujeitos, trabalhadores ou não, com marcadas experiências vitais que não podem ser ignoradas" (p. 58).

Dessa forma, assistimos à iniciativa de alguns governos municipais e estaduais no sentido de promover ações de "capacitação" do corpo docente por meio da formação continuada de professores e do incentivo à produção de material didático voltado para o público jovem e adulto. De acordo com Moll (2004), o descaso com a Educação de Jovens e Adultos pode estar, aos poucos, começando a ser revertido pela ação local dos municípios e seus parceiros:

O papel fundamental que o poder local pode desempenhar neste processo, avançando em relações que permitam a ampliação da esfera pública, sem levar ao descomprometimento governamental, pode estar relacionado à leitura do universo dos sujeitos da educação de jovens e adultos, para além de sua designação como dados estatísticos anônimos. (MOLL, 2004, p. 22)

As ações das universidades com relação à formação do educador de jovens e adultos ainda são tímidas se considerarmos, de um lado, a 
relevância que tem ocupado a EJA nos debates educacionais e, de outro, o potencial dessas instituições como agências de formação. Os trabalhos acadêmicos que se referem à temática, analisados por Machado (2000), alertam que a formação recebida pelos professores, normalmente por meio de treinamentos e cursos aligeirados, é insuficiente para atender às demandas da Educação de Jovens e Adultos. Nesse sentido, concluem que, para se desenvolver um ensino adequado a esse público, são necessários uma formação inicial específica consistente, assim como um trabalho de formação continuada. A autora afirma que "há um desafio crescente para as universidades no sentido de garantir/ampliar os espaços para discussão da EJA, seja nos cursos de graduação, seja nos de pósgraduação e extensão" (MACHADO, 2000, p. 16).

Segundo os dados do INEP de 2002, das 519 Instituições de Ensino Superior (IES) brasileiras que ofertam o curso de Pedagogia e que foram avaliadas pelo Exame Nacional de Cursos, apenas 9 (1,74\%) oferecem a habilitação de EJA: 3 na região Sul, 3 na Sudeste e 3 na região Nordeste (MEC/INEP, 2002). Os dados de 2005 revelam que houve aumento, ainda que pouco expressivo, do número de instituições que oferecem a habilitação de EJA para os cursos de Pedagogia: das 612 contabilizadas, 15 oferecem a habilitação $(2,45 \%)$ e, dos 1698 cursos, há 27 ofertando essa formação específica ${ }^{2}(1,59 \%)$.

Quadro 1:

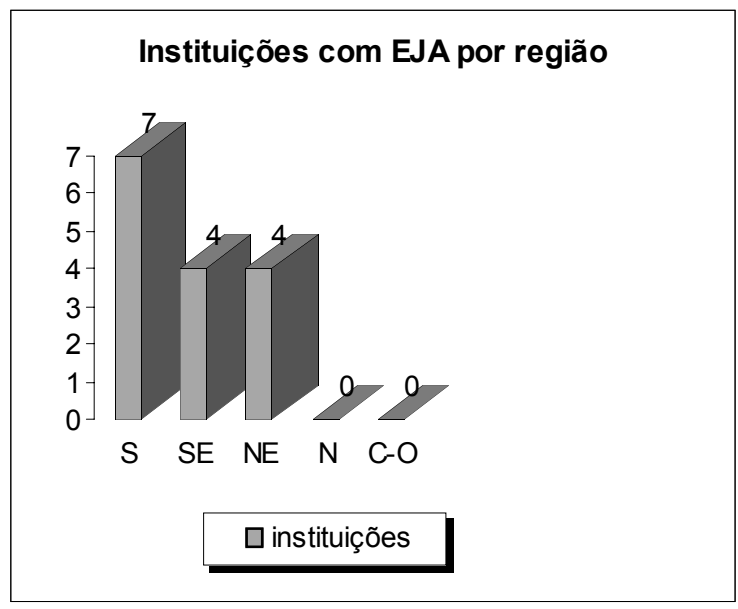

Fonte: dados do INEP de 2005 
Quadro 2:

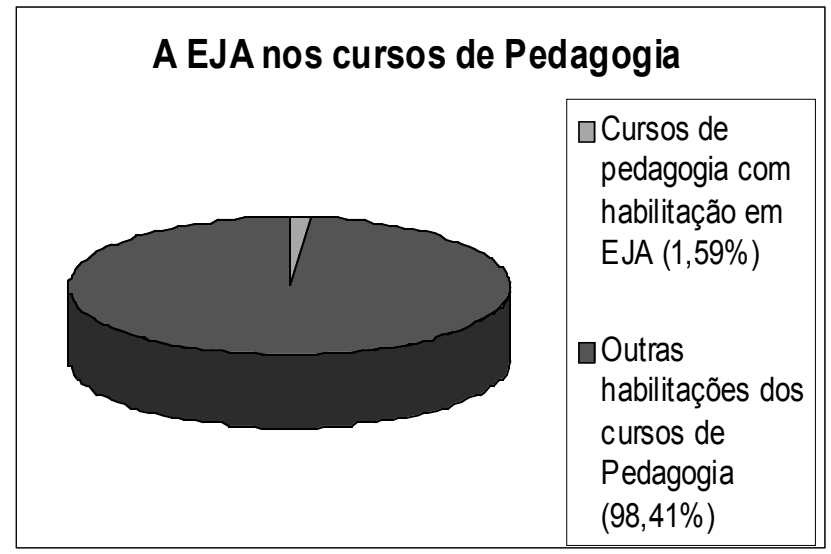

Fonte: INEP, 2005

Dos cursos de Pedagogia com habilitação em EJA, investigamos o oferecido pela Faculdade de Educação da Universidade Federal de Minas Gerais, que a introduziu no currículo em 1986. Embora o curso tenha possibilitado a formação de cerca de 140 profissionais, pela primeira vez se realizou uma pesquisa de "escuta" desses sujeitos e das implicações dessa formação em suas práticas pedagógicas. Nóvoa (1992, p. 10), em seu livro sobre as histórias de vida dos professores, explicita que "esta profissão precisa de se dizer e de se contar: é uma maneira de a compreender em toda a sua complexidade humana e cientifica".

Procuramos discutir as seguintes questões: Qual é o perfil dos educadores de EJA formados nessa faculdade? Até que ponto o curso de Pedagogia, com essa habilitação, contribui para a inserção profissional? Os egressos enfrentaram dificuldades para trabalhar na área em que se formaram? Há casos de formandos que desistiram de atuar por não serem valorizados ou reconhecidos como profissionais qualificados para uma área específica? Em que espaços estão atuando? Que significados os professores da habilitação atribuem à construção dessa formação na faculdade? Despertar a discussão com os educadores egressos da habilitação e com os professores contribui para instigar novas investigações e estudos sobre a formação de um educador para a EJA.

Pesquisando os arquivos da Seção de Ensino da Faculdade, chegamos ao total de 142 alunos formados na habilitação de EJA. Desses, conseguimos nos comunicar com 120, dos quais 9 não chegaram a concluir o curso. Logo, nosso universo foi delimitado em 111 sujeitos. 
Elaboramos um questionário semi-aberto que foi enviado a esses egressos. Com base nos questionários, foi traçado um perfil dos sujeitos e selecionou-se uma amostra para realizar as entrevistas. As principais questões que nos orientaram foram a história de vida do sujeito, a formação na universidade, sua inserção e sua trajetória profissionais ${ }^{3}$. Recebemos 90 questionários ( $81 \%$ dos enviados) e selecionamos, para as entrevistas, 10 egressos que estavam atuando na EJA e 10 que não estavam. Além disso, foram entrevistados três professores da habilitação. Analisando as informações dos questionários, 19 dos 90 egressos $(20 \%)$ estavam trabalhando com a EJA. Daqueles que não atuavam, 50\% trabalhavam em outros espaços educativos e $30 \%$ não atuavam na área de educação. Para compreender o papel da formação inicial na trajetória profissional desses sujeitos, elegemos três categorias de análise: a primeira relacionava-se à inserção profissional e o campo da EJA, buscando conhecer os locais de atuação dos sujeitos, o modo como foram introduzidos no trabalho, a maneira como a formação inicial é reconhecida pelos demais profissionais e o olhar que construíram com relação ao campo. A segunda categoria era sobre escolba da habilitação e o sen lugar na faculdade, que objetivava entender como se deu o processo de escolha e qual é o lugar ocupado por essa formação nessa Instituição. A terceira referia-se à avaliação da habilitação, ou seja, entender, por meio dela, que representações os sujeitos construíram sobre essa formação específica que tiveram na Faculdade.

\section{A FORMACÃO INICIAL EM EJA:}

\section{SIGNIFICADOS ATRIBUÍDOS PELOS EGRESSOS}

\section{E PELOS PROFESSORES DA HABILITAÇÃO}

$\mathrm{Na}$ época da criação da habilitação em Educação de Jovens e Adultos, o currículo era composto pelas habilitações de Administração, Supervisão, Orientação e Inspeção Escolar, as quais eram marcadas por forte dimensão técnica. Segundo os professores entrevistados, essa implementação foi fruto de uma discussão ampla sobre a formação do pedagogo e as possibilidades de sua inserção na sociedade, debate que marcou, durante os anos 1980, muitas universidades e fóruns acadêmicos educacionais brasileiros. Segundo Flávia ${ }^{4}$, ex-professora da habilitação, havia uma "crítica aos conteúdos técnicos, uma visão técnica da pedagogia, o pedagogo enquanto um especialista". Ao mesmo tempo, demonstrava-se a preocupação em formar um profissional "inserido mais próximo dos movimentos sociais", ou, como pondera a professora Tereza: "queríamos 
configurar uma educação crítica, uma educação colada muito nos princípios da educação popular". Na medida em que a EJA teve sua história gerada no seio dos movimentos populares e por meio de experiências vinculadas à educação popular (ARROYO, 2001), pensar um novo currículo para o curso de pedagogia significava acolher a riqueza de tais ações, ampliando o entendimento do que é ser pedagogo.

Uma nova concepção de pedagogo era construída à medida que a própria Faculdade, à semelhança do que ocorria em outras universidades brasileiras no contexto de redemocratização do país, realizava um movimento em direção às classes populares. Nessa época, criaram-se projetos de extensão que mantinham grande interface com a organização dessas camadas sociais. Assim, em atividades extracurriculares, os alunos do curso de Pedagogia vivenciavam experiências pedagógicas voltadas para a educação popular. Concomitantemente, o Programa de Pós-graduação dessa faculdade também tinha uma ação que visava à formação de pesquisadores voltada majoritariamente para os movimentos populares: a grande maioria dos profissionais que ingressava no mestrado atuava nesses espaços ${ }^{5}$.

Segundo Flávia, discutiam-se duas grandes questões: uma relacionada ao desejo dos professores de mudar radicalmente a estrutura do curso de Pedagogia e outra que dizia respeito às possibilidades de o pedagogo formado pela Instituição se inserir em um "mercado" marcado pela presença de um profissional com perfil predominantemente técnico - aquele que estava sendo criticado. Foi construída uma proposta mediadora, em que a habilitação de Educação de Adultos foi introduzida na estrutura antiga, como uma possibilidade de o pedagogo atuar junto aos movimentos sociais e à educação popular. Nas palavras da professora Tereza, "a intenção era ampliar os horizontes de intervenção do pedagogo, e ele poder ser formado além de atuar na escola, ele poder também atuar nesse espaço fora".

É importante salientar que a habilitação contemplava, como sua denominação inicial expressa, o público adulto e, posteriormente, ela incorpora a questão do jovem em sua formação. A primeira configuração da habilitação se deu pela introdução de cinco disciplinas: Fundamentos da Educação de Adultos, Didática, Organização e Currículo da EDA e o estágio de $60 \mathrm{~h}$, que podia ser realizado tanto no espaço escolar quanto em outros espaços. Em 2000, a habilitação passou a ser denominada Educação de Jovens e Adultos, como resultado de discussões e estudos realizados sobre o campo, que evidenciavam a diversificação do público que freqüentava os espaços educativos tradicionalmente vinculados à 
escolarização "não regular". Nessa reforma, as disciplinas de Currículo e de Fundamentos da Educação de Adultos foram substituídas pelas de Educação Matemática, Monografia e Tópicos Especiais em EJA. Nesse momento, as habilitações - Gestão Educacional, Educação Infantil, Alfabetização e Educação de Jovens e Adultos - passaram a ser denominadas de formação complementar.

Se na época da implementação da habilitação havia forte preocupação de formar o pedagogo para se inserir em espaços não escolares, na reforma de 2000 ganha força a necessidade da formação do profissional para atuar na escola. Segundo Ana, tal configuração é resultado "da luta pela democratização do acesso à escola”. Nas entrevistas, os professores concordam que "atualmente, a formação de EJA está muito colada com a formação de um profissional para atuar na escola” (Amélia).

Pensando sobre o caráter da formação, Ana ressalta que a habilitação em EJA está inserida no conjunto de disciplinas que formam profissionais para atuar na sala de aula. $\mathrm{O}$ aluno, ao optar por essa formação complementar, cursará as disciplinas referentes às metodologias de ensino, juntamente com as turmas de Educação Infantil e Alfabetização. Após essa primeira etapa, cursará disciplinas mais específicas: Educação Matemática, Didática, Organização e o Estágio em EJA. Certamente, essa direção assumida pela formação no curso de Pedagogia se vincula ao espaço que, crescentemente, sobretudo após a Constituição de 1988, a EJA tem ocupado nas redes formais de ensino, deixando de ter caráter supletivo, compensatório e extra-oficial para tornar-se um direito ${ }^{6}$.

Em 2002, o corpo docente inicia um novo debate, a fim de avaliar o caráter das habilitações. Segundo Tereza, havia a preocupação de que "a habilitação de EJA não ficasse em um tom só escolar e que não ficasse tão superficial... isso os alunos da antiga habilitação questionavam". Apesar de ainda não ter sido plenamente implementada, na nova reformulação curricular, foram inseridas as disciplinas Alfabetização e Letramento para EJA e Processos Educativos nas Ações Coletivas II.

No que diz respeito às perspectivas da formação complementar, os professores apontam que a questão do educador social está sendo novamente colocada em razão do crescente número de projetos de extensão na área. Os projetos com juventude e movimentos sociais conferem visibilidade a outras possibilidades de atuação no campo, o que, segundo Ana, provoca um "rol de demandas que nós vamos ter que aprender a formar para elas, porque eu acho que nós não sabemos não". Ao mesmo tempo, os 
professores apontam a necessidade de dar visibilidade às ações de EJA da Faculdade e de manter os profissionais que se formam vinculados ao núcleo de pesquisa e ensino, para que seja possível estruturar melhor a área.

Ao apontar as lacunas da formação, Ana pondera que "essa inserção escolar ainda não está bem-caracterizada para atuação do educador de jovens e adultos. As disciplinas não se entendem como disciplinas que são específicas para formação do educador de jovens e adultos". Por isso, considera que é preciso criar competências na faculdade para trabalhar as questões específicas da formação em EJA.

A trajetória da habilitação em EJA no curso de Pedagogia da Universidade pesquisada é relembrada quando os egressos são incentivados a discorrer sobre o porquê da opção, na vida de cada um deles, por essa formação inicial específica. Os dados indicam que a maioria dos egressos havia vivenciado alguma experiência com adultos anteriormente ao curso. Muitas dessas atuações estavam inseridas em projetos sociais de educação: "o meu desejo foi com movimentos sociais, dentro da JOC a gente tinha ações junto ao bairro e à comunidade e nós montamos uma turma de adultos para alfabetizar" (Bruna). O contato com jovens e adultos das camadas populares parecia despertar o interesse em se profissionalizar como educador.

Alguns entrevistados demonstram certo idealismo em suas falas, estreitamente relacionado ao contexto de reformulação dos cursos de Pedagogia e de redemocratização do país característico dos anos 1980: "Então era muito de pensar assim, em que caminhos trilhar dentro desse curso que me permitisse me envolver com o processo de educação libertador, ligado a movimentos culturais, era muito essa... tanto que a minha primeira opção já foi EJA, depois é que eu fui fazer uma habilitação tradicional, né, depois é que eu fiz supervisão escolar" (Carla). Quando optaram, sabiam que o campo de trabalho era difícil, mas persistiram na escolha: "Mas eu queria fazer uma habilitação que eu saísse daqui, pelo menos assim, com aquele sentimento de realização, de tá fazendo uma coisa que eu gostava de fazer e não tá querendo fazer alguma coisa só porque era o melhor pro mercado, sabe, eu queria fazer uma coisa que eu saísse daqui satisfeita com o curso" (Paula).

Sobre essa persistência das alunas em investir na formação em EJA, mesmo sem perspectivas para o campo de trabalho, retomamos à Pedagogia da Esperança de Paulo Freire, que considera que "não há esperança na pura espera, nem tampouco se alcança o que se espera na espera pura, que vira, assim, espera vã” (FREIRE, 1992, p. 10-11). 
Mesmo quando não atuam na EJA, os egressos apontam que a formação possibilitou uma visão mais ampla da educação como um processo que não ocorre só dentro da escola, mas no interior dos movimentos sociais, e que se relaciona à luta por uma sociedade melhor. Ou seja, a formação adquirida potencializava o profissional, mesmo que ele não fosse atuar especificamente com o público jovem e adulto e mesmo que a habilitação não ocupasse lugar de destaque no curso de Pedagogia.

$\mathrm{Na}$ percepção dos egressos da habilitação entrevistados, a herança que legamos da EJA como uma educação "menos importante" do que as outras parece também se refletir no espaço que essa formação ocupa na Instituição. Eles foram unânimes em relatar o lugar desprivilegiado que a habilitação ocupava em relação às demais formações: "Eu sentia, na minha época, que era um lugar que precisava ser ocupado mais" (Daniela). Apontam também as causas de tal situação: "Eu acredito que, na época, faltava divulgação, aquilo que era mais certo de ocorrer todo semestre já estava à disposição, com os professores dos departamentos preparados, agora a EJA era algo do qual se corria atrás e aí, muitas vezes, os alunos pegavam a faculdade de surpresa” (Bruna).

Os entrevistados também evidenciaram razões relacionadas às possibilidades de atuação no campo de trabalho, consideradas restritas, para o lugar ocupado pela formação no cotidiano institucional: "Não tinha muito valor porque sempre houve a ligação entre a formação e o mercado de trabalho, então não se escutava tanto falar na EJA, quem é ele [o profissional], o que vai fazer" (Marília). Esse depoimento, além de explicitar a baixa demanda do campo de trabalho em torno de um profissional formado para atuar em uma modalidade específica de educação, também remete à particularidade desse campo, que se constitui em vários espaços e apresenta grau de "porosidade" que os alunos não vêem nas demais habilitações.

Ao mesmo tempo, alguns egressos reconhecem que, aos poucos, a EJA vai ocupando mais espaço na faculdade: "Agora tem o núcleo de EJA, então a própria habilitação tende a crescer" (Daniela). Esse depoimento remete ao movimento mais amplo de institucionalização da EJA como campo acadêmico, visualizado pelo crescimento dos núcleos de pesquisa ${ }^{7}$ e extensão ${ }^{8}$ voltados para a área, nas universidades.

Mesmo considerando o papel relativamente "marginal" ocupado pela EJA na faculdade pesquisada na época em que cursaram a habilitação e/ou formação complementar, os entrevistados reconhecem que a 
formação oferecida é de qualidade e permite ao profissional "construir uma segurança com relação ao trabalho" (Marília). Além disso, percebem, no dia-a-dia de trabalho, a importância da habilitação: "encontro pessoas que estão administrando projetos de EJA, elaborando propostas, então a gente percebe que falta alguma coisa e esta alguma coisa acontece neste espaço de formação acadêmica" (Clara).

Ao apontarem as lacunas da formação, muitos egressos falam da distância sentida entre a teoria discutida no curso e a prática na EJA: “eu senti falta, por exemplo, de pegar algumas experiências de EJA, pegar talvez um exemplo de uma escola e porque eles estão fazendo isso, isso e assado. Estas relações também com as políticas públicas concretas, o que você vai encontrar no mercado aí, a falta de verbas, etc." (Daniela). Nesse sentido, sugerem algumas inserções, ainda durante o curso, em projetos, na própria universidade, voltados para a educação de jovens e adultos: "Se fosse uma condição para você fazer o curso, fazer um estágio permanente ali no PAJA', não seria interessante? Eu acho isso muito importante para haver este diálogo (...) Uma pessoa que faz a habilitação, mas não passa por uma prática refletida, ela também vai ficar com uma lacuna na formação" (Maria Lúcia).

Outro aspecto ressaltado, diretamente relacionado ao primeiro, refere-se à necessidade de maior vínculo entre a universidade e o campo de trabalho. Segundo os egressos, a aproximação entre essas duas instâncias poderia facilitar a inserção profissional do recém-formado: "que eu me lembre, não tinha muita motivação e informação: olha, tem escola tal para trabalhar, manda currículo, isso não aconteceu. Então eu acho que este compromisso de criar parcerias com as escolas que têm EJA, eu acho que precisava" (Márcia). Atualmente, para promover a maior integração entre a universidade e o campo de trabalho, a faculdade tem investido em duas ações, uma relacionada à promoção de seminários de $\mathrm{EJA}^{10}$, em que a habilitação é divulgada, e outra diz respeito à comunicação da formação inicial nos espaços de estágio freqüentados pelos alunos.

\section{A RELAC̣ÃO ENTRE A FORMAÇÃO INICIAL E A INSERÇÃO NO CAMPO DE TRABALHO}

Os egressos que atuavam na EJA (20\% do total de formados na habilitação) possuem em comum o fato de trabalharem com adultos de classes populares. Parte dos entrevistados não faz desse trabalho o único meio de sobrevivência, a maioria possui outra atuação na própria área da 
educação e há, inclusive, casos de quem atua na EJA como voluntário. Relatam que tanto os baixos salários quanto o baixo nível de profissionalização das ocupações são motivadores para a inserção em outra ocupação. Entre aqueles que, apesar de terem cursado a habilitação, não atuavam na EJA, há relatos que se referem tanto a motivos de ordem pessoal quanto aos relacionados às dificuldades do campo de trabalho. A falta de concursos públicos específicos para o educador de jovens e adultos é apontada como uma das maiores dificuldades que os egressos encontram. Outro fator agravante é que grande parte das turmas de EJA está no formato de projetos/programas que têm como característica a baixa remuneração ou ajuda de custo em forma de bolsa, desestimulando a inserção de profissionais na área. Nesse sentido, Nóvoa (1995) afirma que "é impossível separar o eu profissional do eu pessoal". Dados da vida pessoal dos professores também são relevantes para compreendermos sua trajetória profissional e, em especial, as razões pelas quais não atuaram no campo.

Os depoimentos dos sujeitos sobre como se inseriram profissionalmente na área de EJA e os fatores preponderantes nesse processo nos levam a refletir sobre a relativização do papel ocupado pela formação inicial em cada caso específico. Para alguns daqueles que ingressaram na rede particular, por exemplo, a formação inicial foi essencial: "Eu fui contratada por ter tido a habilitação e uma experiência dentro do projeto da UFMG" (Bárbara). Em outros casos, a formação inicial em EJA parece não ter influenciado na inserção profissional dos entrevistados, como no caso de Aída: "Eu já trabalhava em uma escola da rede privada e a coordenadora perguntou quem tinha o interesse em alfabetizar os funcionários e eu me manifestei, só que o trabalho era voluntário. O fato de eu ter a habilitação não influenciou". Nessa mesma direção, pode ser citado o depoimento de outra ex-aluna da habilitação que, sem nunca ter atuado no campo, afirma que um dos problemas para essa inserção está no fato de que "qualquer pessoa pode estar chegando e lecionando" (Rafaela).

Em outros contextos, como na rede municipal, a habilitação, na maioria dos casos, não foi o fator principal que possibilitou o trabalho com a EJA. Foi levada em consideração apenas a manifestação de interesse por parte do sujeito: "Naquele momento, de fazer a opção de trabalhar na SUDECAP"11, por exemplo, o que contou mais foi a minha vontade" (Clara).

Esses últimos depoimentos remetem à história das práticas educativas voltadas para jovens e adultos. Apesar das conquistas das últimas décadas, que colocam a EJA sob a égide do direito, ainda é corrente a con- 
cepção de que esse campo, como adverte Arroyo, é “um 'lote vago', marcado por um caráter compensatório ou supletivo; emergencial e filantrópico, em que basta a 'boa vontade' para atuar"'12. Esse tratamento compensatório e assistencialista acarreta, para Ribeiro (2001), um prejuízo para a construção da identidade da EJA como modalidade educativa. Segundo Di Pierro (2005):

(...) o paradigma compensatório acabou por enclausurar a escola para jovens e adultos nas rígidas referências curriculares, metodológicas, de tempo e espaço da escola de crianças e adolescentes, interpondo obstáculos à flexibilização da organização escolar necessária ao atendimento das especificidades desse grupo sociocultural (DI PIERRO, 2005, p. 1.118).

Ao sintetizar as principais preocupações com relação à formação docente na esfera da EJA, Haddad e Di Pierro (1994) também destacam essa questão:

Os professores que trabalham na educação de Jovens e Adultos, em sua quase totalidade, não estão preparados para o campo específico de sua atuação. Em geral, são professores leigos ou recrutados no próprio corpo docente do ensino regular. Note-se que na área específica de formação de professores, tanto em nível médio quanto em nível superior, não se tem encontrado preocupação com o campo específico da EJA; devem-se também considerar as precárias condições de profissionalização e de remuneração destes docentes. (HADDAD; DI PIERRO, 1994, p. 15).

A falta de profissionalização do educador de EJA é evidenciada, assim, pelos egressos, como o principal problema para uma inserção profissional específica: "eu tenho notícias da existência de muitos lugares com EJA. Local de atuação tem, não sei se o profissional recebe. Eu acho que dentro disso, a gente tem muito a questão do voluntário na EJA, vão fazer caridade para as pessoas que estão precisando" (Márcia).

Se, de um lado, os entrevistados reconhecem a existência de múltiplos espaços em que o educador de EJA pode atuar, de outro, julgam o campo de trabalho bastante restrito. Essa última representação é particularmente forte entre os egressos que não atuam especificamente com jovens e adultos: "eu acho que o campo é muito restrito, até mesmo por não ser muito divulgado" (Letícia). O campo parece ainda mais restrito, na visão desses entrevistados, na medida em que, para nele se inserir, seria necessária uma indicação de quem já trabalha em lugares onde esse tipo de educação é ofertada: "Eu levei currículo para um monte de empresa, um monte de lugar, cheguei até a fazer teste na Federação das Indústrias para entrar no SESI, mas aí, quando eu fui ver, era uma coisa 
meio de carta marcada" (Alice). Na mesma direção, manifesta-se outra entrevistada: "Eu não procurei não... eu acredito muito em peixadas, eu sei de algumas empresas que têm esse projeto de Educação de Jovens e Adultos, sei que algumas empresas como a Coca-Cola e outras têm, mas eu tinha amigos que me informavam como funcionavam as coisas, mas de qualquer forma eu não consegui entrar" (Rafaela).

Percebe-se que aqueles egressos que não atuam em EJA parecem ter construído uma visão negativa do campo de trabalho voltado para esse público específico. Muitas vezes, a estabilidade profissional já adquirida e a visão de que o campo da EJA é restrito para atuação fizeram com que muitos sujeitos não investissem na procura por trabalho na área. Em outros casos, algumas tentativas frustradas os levaram a desistir de buscar atuação no campo.

$\mathrm{Na}$ visão dos professores que atuam/atuavam na habilitação, é preciso que a universidade participe da constituição do próprio campo, ainda caracterizado pela dispersão. Consideram importante a participação em "movimentos de constituição do fórum, de convênio, de uma rede com os espaços que acontecem a EJA" (Ana). Amélia afirma também que é preciso existir uma divulgação maior da universidade: "Divulgação mais agressiva, no sentido da gente tomar mais iniciativa, bater mais nas portas para a gente se apresentar, enquanto assim... existe essa formação desse profissional, que as secretarias fiquem a par de que a Universidade forma esse profissional, então, quando for pensar em abrir edital para concurso, que contemple essa área" (Tereza).

Ressalta também que existe uma tensão entre a formação e o "mercado", pois ao mesmo tempo em que é preciso contemplar as demandas do campo de trabalho, é necessário questioná-lo e fazê-lo avançar.

Por meio dos relatos, percebemos que o campo da EJA não construiu, ainda, o consenso de que possui especificidade que requer um profissional preparado para o exercício da função. As concepções de EJA variam dependendo do lugar em que ela é oferecida. Enquanto há lugares que se baseiam na idéia de que "qualquer pessoa pode ensinar para jovens e adultos", há outros que enxergam a habilitação como um requisito essencial e outros, ainda, que concebem que a formação inicial, apesar de seu valor, não é o preponderante para o trabalho.

\section{CONSIDERACִÕES FINAIS}

Neste trabalho, analisamos questões como a inserção profissional dos sujeitos, o campo de trabalho em EJA, a opção e avaliação 
da habilitação e seu lugar no espaço acadêmico. Apesar de cada entrevista ser fruto de uma vivência singular, pudemos extrair alguns traços em comum nos depoimentos (NÓVOA, 1992). As entrevistas com os professores nos permitiram reconstituir a história da habilitação e seu significado na faculdade pesquisada. Por meio da análise dos depoimentos, percebemos que a configuração da formação em EJA guarda estreita relação com a dinâmica social vivenciada. Assim, de maneira mais visível, encontra-se aberta às demandas apresentadas pelos movimentos sociais.

Constata-se que, mesmo com a crescente visibilidade que tem tido a EJA, seja na instância das práticas, seja como campo de estudos e pesquisas, ainda não existe efetiva demanda para a formação específica do educador que atua com esse público no campo de trabalho. Mesmo que a formação inicial ofertada pela universidade seja considerada de qualidade, os egressos não necessariamente têm essa qualificação valorizada no momento da inserção profissional. Não existe, assim, relação estreita entre formação inicial na universidade e campo de atuação. Essa situação pode ser, pelo menos parcialmente, explicada pela configuração histórica da EJA no Brasil, fortemente marcada pela concepção de que a educação voltada para aqueles que não se escolarizaram na idade regular é supletiva e, como tal, deve ser rápida e, em muitos casos, aligeirada (DI PIERRO, 2005).

Nessa perspectiva, também o profissional que nela atua não precisa de preparação longa, aprofundada e específica. O próprio campo de atuação do profissional de EJA, por ser amplo e pouco definido, parece dar aos egressos a sensação de que sua formação inicial, embora necessária, não é essencial. Essa amplitude e "porosidade" da área dificultam, por outro lado, a própria ação da universidade, que, por meio de algumas reformas curriculares, busca aproximar a formação inicial do educador de EJA às demandas do campo de trabalho e, ao mesmo tempo, às necessidades colocadas para a área pelas pesquisas que vêm sendo realizadas. Certamente, o crescimento do lugar que a EJA tem ocupado nas universidades, que se relaciona com o próprio fortalecimento da área (como prática pedagógica nas redes formais de ensino, nos movimentos sociais e em projetos de extensão universitária e de pesquisa), tem contribuído para que ela se (re)configure e se fortaleça (ARROYO, 2005).

Há que se pressionar o Ministério da Educação para a tomada de iniciativa no que diz respeito à formação desse educador. Constatam-se avanços na concepção de EJA adotada pelo Ministério: 
"O momento é de construção de um novo desenho para a alfabetização e para a EJA como um todo, e vem sendo feito a partir de um diálogo que aponta para uma reconfiguração mais pública da educação de jovens e adultos. Quanto às concepções de EJA correntes, ainda que saiba da distância entre as formulações e as práticas, o MEC vem adotando enfoques de alfabetização e de educação de jovens e adultos mais amplos, intersetoriais, visando a incorporá-las aos sistema nacional de educação, pelo fato de não ser mais possível tratá-las de forma isolada dos sistemas de ensino..." (HENRIQUES; IRELAND, 2005. p. 354).

Entretanto, uma linha de preocupação que se traduza em intencionalidade ainda está por acontecer. A constituição de um quadro profissional - formado nos cursos de Pedagogia, nas licenciaturas e nas redes de educação formal e não-formal - para atuar junto a um público específico contribuirá para o fortalecimento da área, para a (re)configuração desse campo de trabalho e, certamente, para o melhor atendimento de parcelas significativas da população que foram precocemente excluídas das ações de escolarização.

\section{REFERÊNCIAS}

ANDRÉ, M. A.; ROMANOWSKI, J. P. Estado da arte sobre formação de professores nas dissertações e teses dos Programas de Pós-Graduação das universidades brasileiras (1990-1996). In: ANPED, 22, 1999, Caxambu. Anais..., Caxambu: Associação Nacional de Pós-graduação e Pesquisa em Educação, 1999.

ARROYO, M. Ciclos do desenvolvimento humano e formação de professores. Educação \& Sociedade, Campinas, v.20, n. 68, p. 143-162, dez.1999.

ARROYO, M. A educação de jovens e adultos em tempos de exclusão. Revista de Educação de Jovens e Adultos, São Paulo, n.11, abr. 2001.

ARROYO, M. Educação de jovens-adultos: um campo de direitos e de responsabilidade pública. In: SOARES, L.; GIOVANETTI, M. A.; GOMES, N. L. (Org.). Diálogos na educação de jovens e adultos. Belo Horizonte: Autêntica, 2005. p.19-50.

CARVALHO, Carlos Fabian de. A educação de jovens e a universidade: a experiência do Núcleo de Educação de Jovens e Adultos da Universidade Federal do Espírito Santo. 2004. Dissertação (Mestrado em Educação) - Faculdade de Educação, Universidade Federal de Minas Gerais, Belo Horizonte, 2004.

CONGRESSO NACIONAL DE EDUCAÇÃO DE ADULTOS, 1, 1947, Rio de Janeiro. R.J. Ministério da Educação e Saúde, 1950.

CONGRESSO NACIONAL DE EDUCAÇÃO DE ADULTOS, 2, 1958, Rio de Janeiro. Teses e Comunicados. R.J: Ministério da Educação e Saúde, 1958. (Mimeogr.).

DI PIERRO, Maria Clara. Notas sobre a definição da identidade e das políticas públicas de educação de jovens e adultos no Brasil. Educação e Sociedade, Campinas, número especial, v.26, out. 2005.

EDUCAÇÃO EM REVISTA. Belo Horizonte: Faculdade de Educação da UFMG, n. 32, 2000 (Dossiê: Educação de Jovens e Adultos).

FONSECA, M.C. F. R.; PEREIRA, J. E. D. O significado de um projeto de extensão universitária 
na formação inicial de Educadores de Jovens e Adultos. Relatório Parcial de Pesquisa, 2000.

FREIRE, Paulo. Pedagogia da Esperança: um reencontro com a pedagogia do oprimido. São Paulo: Paz e Terra, 1992.

HADDAD, S. Estado da arte da Educação de Jovens e Adultos. In: REUNIÃO ANUAL DA ANPED, 23, 2000, Associação Nacional de Pós-graduação e Pesquisa em Educação, Caxambu, 2000.

HADDAD, S.; DI PIERRO, M. C. Diretrizes de política nacional de educaşão de jovens e adultos: consolidação de Documentos 1985/94. São Paulo, ago.1994.

KLEIMAN, A. (org.). O ensino e a formação do professor: alfabetização de jovens e adultos. Porto Alegre: Artes Médicas, 2000.

LDB - Leis de Diretrizes e Bases da Educação Nacional. LEI No. 9.394, de 20 de dezembro de 1996. D.O. U. de 23 de dezembro de 1996.

MACHADO, M. M. A prática e a formação de professores na EJA: uma análise de dissertações e teses produzidas no período de 1986 a 1998. In: Reunião anual da ANPED, 23, 2000, Associação Nacional de Pós-graduação e Pesquisa em Educação, Caxambu, 2000. (Edição eletrônica).

MACHADO, M. M. Formação de professores de EJA: como as pesquisas tratam este tema? Revista de Educação de Jovens e Adultos, São Paulo, n. 13, dez.2001.

MINISTÉRIO DA EDUCAÇÃO. Instituto Nacional de Estudos e Pesquisas Educacionais. Exame Nacional de Cursos ENC/2001: Análise dos Projetos Pedagógicos dos Cursos de Pedagogia. out. 2002.

MINISTERIO DA EDUCACAO. Conselho Nacional de Educação. Disponível em: $<$ www.mec.gov.br/cne> Acesso em 15 mar. 2006.

MOLL, Jaqueline. EJA como política publica local: atores sociais e novas possibilidades educativas: Educação e Realidade. Porto Alegre, v.01, n.01, p. 09-24, jul./dez. 2004.

NÓVOA, A. Professor e sua formação. São Paulo: Dom Quixote, 1995.

NÓVOA, A. Os professores e as histórias da sua vida. In: NÓVOA, A. (Org) Vidas de Professores. Portugal: Porto Editora, 1992.

RIBEIRO, V. M. A formação de educadores e a constituição da educação de jovens e adultos como campo pedagógico. Educação \& Sociedade, Campinas, v.20, n. 68, dez. 1999. RIBEIRO, V. M. A promoção do alfabetismo em programas de educação de jovens e adultos. In: RIBEIRO, V. M.(org.) Educação de Jovens e Adultos: novos leitores, novas leituras. Campinas: Mercado de Letras, 2001.

SANTOS, G. L. Educação ainda que tardia: a exclusão da escola e a reinserção em um Programa de Educação Jovens e Adultos entre adultos das camadas populares. Dissertação (Mestrado em Educação) - Faculdade de Educação, Universidade Federal de Minas Gerais, Belo Horizonte, 2001.

SOARES, Leôncio José Gomes. Educação de Jovens e adultos. Rio de Janeiro: DP\&A, 2002. UNESCO, MEC. Declaração de Hamburgo sobre Educação de Adultos - V CONFINTEA. Brasília: MEC, 2004.

VÓVIO, C; BICCAS, M. Formação de educadores: aprendendo com a experiência. Revista de Educação de Jovens e Adultos, São Paulo, n.13, dez. 2001. 


\section{NOTAS}

${ }^{1}$ I CONGRESSO (1947) e II CONGRESSO (1958).

2 www.inep.gov.br

${ }^{3}$ Estudos sobre egressos orientaram os procedimentos de coleta de dados, como Santos (2001).

${ }^{4}$ Para garantir o anonimato dos sujeitos entrevistados, todos os nomes usados neste artigo são fictícios.

${ }^{5}$ Ver Arroyo (1999).

${ }^{6}$ Ver, entre outros, Haddad e Di Pierro (1994), sobre as políticas públicas contemporâneas voltadas para a EJA.

${ }^{7}$ Ver o número 32 do periódico Educação e Revista (2000).

${ }^{8}$ Ver Carvalho (2004).

${ }^{9}$ Projeto de Alfabetização de Jovens e Adultos.

${ }^{10}$ Seminário que reuniu egressos e alunos da habilitação com coordenadores de programas de EJA de redes de ensino da região metropolitana de Belo Horizonte para expor o perfil de educadores com que trabalham.

${ }^{11}$ Superintendência de Desenvolvimento da Capital.

${ }^{12}$ Fala proferida no $3^{\circ}$ Seminário de Pesquisa "A formação e a atuação do pedagogo na EJA", em 30/9/2004, na faculdade pesquisada. Ver, também, Arroyo (2005).

Recebido: $17 / 10 / 06$

Aprovado: 13/06/07

\section{Contato:}

Rua Borges, $n^{\circ} 33$, apto 201

Jaraguá

Belo Horizonte - MG

BRASIL

CEP: 31270-150

E-mail:formacaoeja@yahoo.com.br 